\title{
CONF-871036--15
}

\section{Production of Long-Lived Activities in Fusion Materials}

CONF-871036--15

DE88 002963

\author{
L. R. Greenwood and D. L. Bowers ${ }^{a}$ \\ Chemical Technology Division \\ ${ }^{a}$ Analytical Chemistry Laboratory \\ Argonne National Laboratory \\ Argonne, IL 60439 USA
}

\section{DISCLAIMER}

This report was prepared as an account of work sponsored by an agency of the United States Government. Neither the United States Government nor any agency thereor, nor any of their employees, makes any warranty, express or impiled, or assumes any legal liability or responsibility for the accuracy, completeness, or usefulness of any information, apparatus, product, or process disclosed, or represents that its use would not infringe privately owned rights. Reference herein to any specific ccmmercial product, process, or service by trade name, trademark, manufacturer, or otherwise does not necessarily constitute or imply its endorsement, recommendation, or favoring by the Uniced States Governmen: or any agency thereof. The views and opinions of authors expresset herein do not necessarily siate or reflect those of tie United States Government or any agency thereaf.

\section{Proceedings of Third International Conference on Fusion Reactor Materials October 4-8, 1987, Karlsruhe, F. R. Germany}

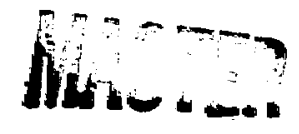




\title{
Production of Long-Lived Activities in Fusion Materials
}

\author{
L. R. Grcenwcod and D. L. Bowers \\ Argonne National Laboratory, Argonne, II USA
}

\begin{abstract}
Neutron cross sections have been measured near $14 \mathrm{MeV}$ for reactions leading to long-lived radioisotopes in fusion materials. Results are summarized for various reactions leading to ${ }^{26} \mathrm{Al}(720,000 \mathrm{y}),{ }^{55} \mathrm{Fe}(2.73 \mathrm{y}),{ }^{63} \mathrm{Ni}(100 \mathrm{y}),{ }^{59} \mathrm{Ni}(76,000 \mathrm{y})$, and ${ }^{94} \mathrm{Nb}(20,300 \mathrm{y})$. New data is presented for the production of ${ }^{91} \mathrm{Nb}(680 \mathrm{y})$ from ${ }^{92} \mathrm{Mo}$, and for ${ }^{93} \mathrm{Mo}(3500 \mathrm{y})$ and ${ }^{93 \mathrm{~m}} \mathrm{Nb}(13.6 \mathrm{y})$ from ${ }^{94} \mathrm{Mo}$. Our measurements suggest that the half-life of ${ }^{91} \mathrm{Nb}$ may be shorter $(350 \mathrm{y})$ than previous estimates. Measured cross sections are used to predict the production of these isotopes for various fusion reactor designs.
\end{abstract}

\section{Introduction}

Previously we have reported measurements of various neutron reaction cross sections leading to long-lived radioisotopes in fusion reactor materials. ${ }^{1-8}$ Such data are needed to assess possible restrictions on the waste disposal of materials. The cross sections are also used for neutron dosimetry, plasma diagnostics, and reactor maintenance applirations. In particular we have focussed on the most important long-lived radioisotopes formed by $(n, 2 n)$ reactions near $14 \mathrm{MeV}$. Since these reactions generally have thresholds above $10 \mathrm{MeV}$, the $14 \mathrm{MeV}$ cross section is usually sufficient to determine production rates in fusion materials. A wide range of materials have been irradiated at the Rotating Target Neutron Source (RTNS) II at Lawrence Livermore National Laboratory to neutron fluences on the order of $10^{22}$ $\mathrm{n} / \mathrm{m}^{2}$. A variety of techniques have been used to measure the activities following radiochemical separations.

\section{Experimental Procedures}

Samples were prepared from the pure metals of $\mathrm{Al}, \mathrm{Fe}, \mathrm{Mo}, \mathrm{Cu}, \mathrm{Zr}, \mathrm{Ni}$, and $\mathrm{Nb}$ and the separated isotopes of ${ }^{56} \mathrm{Fe},{ }^{60} \mathrm{Ni},{ }^{64} \mathrm{Ni},{ }^{94} \mathrm{Zr}$, and ${ }^{94} \mathrm{Mo}$. The separated ${ }^{94}$ Mo isotope consisted of a metallic powder pressed into thin discs measuring 3.0 $\mathrm{mm}$ o.d. by $1 \mathrm{~mm}$ long. The ${ }^{94} \mathrm{Mo}$ enrichment was $92.03 \%$ with $5.2 \%{ }^{95} \mathrm{Mo}$ and less than $1 \%$ of the other Mo isotopes. All of the samples were irradiated in thin aluminum tubing along with dosimetry samples. Several irradiations were conducted at the RTNS II using both short irradiations close to the source and longer, piggyback runs farther away. Details concerning the neutron energy spectra at RTNS II have been published previously. ${ }^{1,3}$ In all cases, the neutron fluences were determined from radiometric dosimetry data based on either the ${ }^{93} \mathrm{Nb}(\mathrm{n}, 2 \mathrm{n}){ }^{92 m} \mathrm{Nb}(10$ day) and ${ }^{54} \mathrm{Fe}(\mathrm{n}, \mathrm{p}){ }^{54} \mathrm{Mn}(312$ day) reactions. Measurements are thus referenced to 
standard cross sections of $463 \mathrm{mb}( \pm 4 \%)$ for ${ }^{93} \mathrm{Nb}^{9}$ or to values between $331 \mathrm{mb}$ $(14.5 \mathrm{MeV})$ and $303 \mathrm{mb}(14.8 \mathrm{MeV})( \pm 7 \%)$ for ${ }^{54} \mathrm{Fe}^{1}$. Many dosimeters were used to map the neutron fluence over the sample assemblies. Radiometric measurements of the samples themselves were used to further refine the neutron fluences relying on previously reported data near $14 \mathrm{MeV}$. The precise geometry was determined for each sample from the overall map of the neutron fluence. The average angle then determines the average neutron energy for each sample based on the calculated neulron spectra. 'The neutron energies have a typical spread (fwhm) of about 0.4 MeV.

In most cases, radiochemical separations were used to isolate the desired activity from interfering species. Details of these separations were published previously. ${ }^{\text {? }}$ Gamma and $x$-ray spectroscopy were performed on most of the samplas using highpurity, thin-window germanium detectors. This technique provided a good monicor for the presence of undesirable activities. Direct gamma measurements were used to detect ${ }^{94} \mathrm{Nb},{ }^{91 \mathrm{~m}} \mathrm{Nb}$, and selected samples of ${ }^{26} \mathrm{Al}$. X-ray measurements were performed for ${ }^{59} \mathrm{Ni},{ }^{919} \mathrm{Nb},{ }^{93} \mathrm{Mo}$, and ${ }^{93 \mathrm{~m}} \mathrm{Nb}$. Liquid scintillation spectrometry was used to detect ${ }^{55} \mathrm{Fe}$ which decays by electron capture and the low-energy beta decay of ${ }^{63} \mathrm{Ni}$. In these cases, radiochemical separations and analyses of the energy spectra were critically important. The energy spectra of the measured activities were matched to standard spectra from similarly prepared samples ( ${ }^{55} \mathrm{Fe},{ }^{63} \mathrm{Ni}$ ) to insure proper identification. The relatively new technique of ccelerator mass spectrometry was used to detect ${ }^{25} \mathrm{Al}$.

\section{Summary of Previous Measurements}

All of the reactions which we have studied are listed in Table I and reíerences are given for each measurement. The cross sections for these reactions are summarized in Table II and compared to previous data. Activation cross sections for 22 reactions were measured at five energies between 14.5-14.9 MeV at the RTNSII, and these data were very useful in refining neutron fluence maps for each irradiation. The ${ }^{27} \mathrm{Al}(\mathrm{n}, 2 \mathrm{n})$ data include measurements to the ground state $(720,000 \mathrm{y})$ and isomeric state (6.34s). The ${ }^{54} \mathrm{Fe}(\mathrm{n}, 2 \mathrm{n})$ measurements ${ }^{5}$ to ${ }^{53} \mathrm{Fe}$ have been shown to be quite useful for plasma diagnostics at fusion reaciors. ${ }^{6}$ Furthermore, the reaction is of interest since ${ }^{53} \mathrm{Fe}$ decays to ${ }^{53} \mathrm{Mn}\left(3.7 \times 10^{6} \mathrm{y}\right)$. Due to the very steep energy dependence of these two reactions near $14 \mathrm{MeV}$, data is not included in Table II or in later estimates of fusion reactor activities. Additional measurements are in progress or are planned, as detailed in Table $I$.

\section{New Measurements for Mo Reactions}

We have published results for the production of $91 \mathrm{~m} \mathrm{Nb}$ and ${ }^{94} \mathrm{Nb}$ from natural and enriched ${ }^{94} \mathrm{Mo}$ targets. ${ }^{2}$ New measurements have been completed for ${ }^{91} \mathrm{~s} \mathrm{Nb}$, ${ }^{93} \mathrm{mb}$, and ${ }^{93} \mathrm{Mo}$ from these same targets. Samples were dissolved in a mixture of 
$\mathrm{HCl}$ and $\mathrm{HNO}_{3}$. Sinall aliquots were then flame dried on tantaium discs and covered with a thin layer of tape for $x$-ray counting. The deposits generally measured about $1 \mathrm{mg}$ of Mo spread over an area of about $0.5 \mathrm{~cm}^{2}$. In this way self-absorption corrections were less than $1 \%$ for $x$-rays in the $15-19 \mathrm{keV}$ region. Absolute calibration of the detector was determined with a ${ }^{93 \mathrm{~m}} \mathrm{Nb}$ x-ray standard (NBS-SRM4267). ${ }^{93 \mathrm{~m}} \mathrm{Nb}$ has a half-life oi $13.6 \pm 0.3$ years and the $\mathrm{K} \times$-ray (16.5-19.1 keV) intensity is $10.57 \pm 0.54 \%$. The half-life of ${ }^{93} \mathrm{Mo}$ is $3500 \pm 700$ years and it has the same $\mathrm{x}$-rays us ${ }^{93 \mathrm{~m}} \mathrm{Nb}$ except that the intensity is $73.0 \pm 2.7 \%$. ${ }^{91 g} \mathrm{Nb}$ decays with a lifetime of $680 \pm 130$ years and the $\mathrm{K} x$-rays $(15.7-18.1 \mathrm{keV})$ have an intensity of $63.6 \pm 2.2 \%$. All of the above decay data is taken from reference 10 .

Since we irradiated both natural Mo and ${ }^{94}$ Mo-enriched samples, measurements of the $K x$-ray activity can be used to uniquely determine the fraction of the activity in each sample which is due to either ${ }^{92}$ Mo or ${ }^{94} \mathrm{Mo}$. At tite long decay times of our measurements (1090 days), there are no other known cources of $\mathrm{Nb}$ or $\mathrm{Zr}$ K x-rays from the other Mo isotopes, except for very long-lived isotopes such as ${ }^{92} \mathrm{Nb}\left(3.7 \times 10^{7} \mathrm{y}\right)$ and ${ }^{93} \mathrm{Zr}\left(1.5 \times 10^{6} \mathrm{y}\right)$. Four samples were counted (2 natural, 2 enriched) and a simultaneous fit to the data yields the cross section values listed in Table III. In the case of ${ }^{92} \mathrm{Mo}$, the only known activity with $\mathrm{x}$-rays in this energy region is ${ }^{9 i g} \mathrm{Nb}$. The 62 day isomer of ${ }^{91 \mathrm{~m}} \mathrm{Nb}$ has already decayed away in these samples. ${ }^{919} \mathrm{Nb}$ can be made by several reactions, primarily ${ }^{92} \mathrm{Mo}(\mathrm{n}, 2 \mathrm{n}){ }^{91}$ Mo which rapidly decays to ${ }^{91} \mathrm{Nb}$. Although there is an isomer in ${ }^{91} \mathrm{Mo}$ and in ${ }^{91} \mathrm{Nb}$, all of these reaction products eventually decay to ${ }^{91} \mathrm{Nb}$. ${ }^{91} \mathrm{Nb}$ can also be made by the ${ }^{92} \mathrm{Mo}(\mathrm{n}, \mathrm{d}+\mathrm{np}+\mathrm{pn})$ reactions. Hence, our cross section value represents the net production of ${ }^{919} \mathrm{Nb}$ from ${ }^{92} \mathrm{Mo}$.

In the case of ${ }^{94} \mathrm{Mo}$, we can make ${ }^{93} \mathrm{Mo}$ from the $(n, 2 n)$ reaction and ${ }^{93 \mathrm{~m}} \mathrm{Nb}$ from the $(n, d+n p+p n)$ reactions. ${ }^{93} \mathrm{mb}$ can also be made from the $(n, t+n d+n n p)$ reactions on ${ }^{95} \mathrm{Mo}$; however ${ }^{95} \mathrm{Mo}$ is only $5.18 \%$ of the enriched sample and thus can only make a minor contribution $(\prec 1 \%)$. The situation is further complicated by the fact that ${ }^{93} \mathrm{Mo}$ decays to ${ }^{93 \mathrm{~m}} \mathrm{Nb}$. We plan to perform a radiochemical separation of $\mathrm{Nb}$ and $\mathrm{Mo}$ in order to uniquely determine the cross sections for both species. However, at present we can only place limits on the cross sections for both reactions. The decay of ${ }^{93} \mathrm{Mo}$ to ${ }^{93 \mathrm{~m}} \mathrm{Nb}$ is rather siow due to the long half-life of 3500 year and we calculate that at least $2 \%$ of the present activity must be due to ${ }^{93 \mathrm{~m}} \mathrm{Nb}$. Hence, we can place upper limits on both cross sections, as is done in Table III. It is, however, most probable that we produced more ${ }^{93} \mathrm{Mo}$ than ${ }^{93 m} \mathrm{Nb}$ during the irradiation, as discussed below.

\section{Comparison With Previous Data}

There are no known previous measurements of the ${ }^{94} \mathrm{Mo}(\mathrm{n}, 2 \mathrm{n})^{939} \mathrm{Mo}$ cross section. The cross section to the $6.9 \mathrm{hr}$ isomeric state of ${ }^{83} \mathrm{Mo}$ is reported to be 2.4-6.4 
$\mathrm{mb}^{11,12,13}$; however, the reaction proceeds mainly to the ground state of ${ }^{93} \mathrm{Mo}$ and the total cross section should be much larger.

Haight, et al. , ${ }^{14}$ have reported a value of $9 \pm 3 \mathrm{mb}$ for the ${ }^{94} \mathrm{Mo}(\mathrm{n}, \mathrm{d})$ reaction cross section. This would be quite consistent with our results; however, our measurements also include other possible reaction channels such as ${ }^{94} \mathrm{Mo}(\mathrm{n}, \mathrm{np}+\mathrm{pn})$.

We have used the THRESH2 $2^{15}$ semi-empirical computer code to estimate the strength of various reaction cross sections in order to gain some insight concerning the reiative importance of unobserved reaction's. These calculations predict a relatively flat energy dependence near $14 \mathrm{MeV}$ for the ${ }^{94} \mathrm{Mo}(\mathrm{n}, 2 \mathrm{n})$ reaction with a cross section of about 1 barn. This calculation is close to our naximum value of $810 \mathrm{mb}$. THRESH also predicts that the ${ }^{94} \mathrm{Mo}$ production cross section for ${ }^{93 \mathrm{~m}} \mathrm{Nb}$ is $51 \mathrm{mb}$ and that the (n,np+pn) cross sections are about equal to the $(n, d)$ value. However, these reaction cross sections are steeply rising near $14 \mathrm{MeV}$. If we assume that the ratio of the production cross sections from THRESH2 for ${ }^{93} \mathrm{Mo} /{ }^{93 \mathrm{~m}} \mathrm{Nb}$ is roughly correct, then we would estimate that the ${ }^{91} \mathrm{Mo}(\mathrm{n}, 2 \mathrm{n})^{93}$ Mo cross section is about 280 $\mathrm{mb}$ and that for ${ }^{94} \mathrm{Mo}(\mathrm{n}, \mathrm{x})^{93 \mathrm{~m}} \mathrm{Nb}$ is about $17 \mathrm{mb}$. This latter value would agree with the $(n, d)$ measurement ${ }^{14}$ assuming equal strength for the $(n, n p+p n)$ reactions.

There have been several measurements ${ }^{16-18}$ of the ${ }^{92} \mathrm{Mo}(\mathrm{n}, 2 \mathrm{n})^{91} \mathrm{Mo}$ reaction to both the ground and isomeric states. Unlike the ${ }^{94} \mathrm{Mo}(\mathrm{n}, 2 \mathrm{n})$ reaction, the ${ }^{92} \mathrm{Mo}(\mathrm{n}, 2 \mathrm{n})$ cross section is steeply rising with energy near $14 \mathrm{MeV}$. Hence, some care must be taken in comparisons with our data since our energy resolution is about 0.4 MeV. Previous measurements give a value of about $200-250 \mathrm{mb}$ in our energy region between 14.5-14.9 MeV. However, our measurements also include the production of ${ }^{919} \mathrm{Nb}$ by the ${ }^{92} \mathrm{Mo}(\mathrm{n}, \mathrm{d}+\mathrm{np}+\mathrm{pn})$ reactions. Haight, et ai. ${ }^{14}$ measured a value of $22 \pm 7 \mathrm{mb}$ for the $(\mathrm{r}, \mathrm{d})$ reaction at $14.8 \mathrm{MeV}$. Using the THRESH2 computer code, we estimate that the $(n, p n+n p)$ reaction cross sections sum to about $70 \mathrm{mb}$. Thus the total production cross section of ${ }^{91 \mathrm{~g}} \mathrm{Nb}$ should be about $300 \mathrm{mb}$, much less than our measurement of $603 \mathrm{mb}$.

There are several possible explanations for the discrepancy between our measurements and previous data for the production of ${ }^{919} \mathrm{Nb}$ from ${ }^{92} \mathrm{Mo}$. Since our measurement is based on the strength of the $\mathrm{Zr} K \mathrm{~K}$-rays, it is possible that there are other contributing isotopes. However, due to the long decay time before anaiysis (1090 days), we are unable to jdentify any known interferences from other Mo isotopes or impurities in the material. It may also be that the unobserved ${ }^{92} \mathrm{Mo}(\mathrm{n}, \mathrm{np}+\mathrm{pn})$ reactions have a much larger cross section than predicted by THRESH2; however, this seems highly unlikely since we expect these reactions to be much weaker than the $(n, 2 n)$ reaction. A more likely explanation is that our measurements could be reconciled with previous data if the half-life of ${ }^{91} \mathrm{Nb}$ were reduced to about 350 years. The present value of $680 \pm 130$ years has a rather large uncertainty (19\%). Further measurements are needed to resolve this issue. 


\section{Discussion and Conclusions}

Further measurements are in progress to improve our Mo results. We plan to chemically separate $\mathrm{Mo}$ and $\mathrm{Nb}$, thereby resolving the cross sections for the production of ${ }^{93} \mathrm{Mo}$ and ${ }^{93 \mathrm{~m}} \mathrm{Nb}$ from ${ }^{94} \mathrm{Mo}$. Higher-resolution x-ray measurements may also help to resolve the $\mathrm{Nb}$ and $\mathrm{Zr} x$-rays and should separate any possible interferences with the ${ }^{91} \mathrm{Nb}$ reaction.

The measured neutron cross sections can be ueed to calculate the production of long-lived isotopes in fusion reactor materials, as shown in Table IV. These calculations are for the STARFIRE ${ }^{19}$ fusion reactor design for a six year operating time (21.6 MW-y/m $\left./ \mathrm{m}^{2}\right)$; however, effects due to thermal neutrons have been neglected due to uncertainties in shielding calculations. In most cases, the activation is mainly due to the interaction with $14 \mathrm{MeV}$ neutrons since there is no signifcant neutron flux above the typical threshold energies of $7.13 \mathrm{MeV}$. However, in the case of the ${ }^{63} \mathrm{Cu}(\mathrm{n}, \mathrm{p})$ reaction, lower energy neutrons increase the production of ${ }^{63} \mathrm{Ni}$ significantly. Since we do not know the energy-dependent cross section for this reaction, we assumed that the relative contritution from lower energy neutrons would be about equal to that from the $14 \mathrm{MeV}$ neutron flux, as reported previously. ${ }^{17}$ Calculations were not included for the ${ }^{2 \gamma} \mathrm{Al}$ and ${ }^{54} \mathrm{Fe}(\mathrm{n}, 2 \mathrm{n})$ reactions since the activities are crucially dependent on the plasma temperature and neutral beam heating parameters. ${ }^{6}$ In the case of ${ }^{93} \mathrm{Mo}$ and ${ }^{93 \mathrm{~m}} \mathrm{Nb}$, we can only place limits on the activities since we cannot separate them in our data. For ${ }^{91} \mathrm{Nb}$, we note that the cross sections are steeply rising near $14 \mathrm{MeV}$ and we have thus used a lower value in our fusion calculations based on the energy dependence in previous ( $n, 2 n$ ) reaction data.

The fusion reactor activities reported in Table IV can be compared to previous estimates. ${ }^{20}$ This comparison is not straightforward since we have neglected transmutation effects due to thermal neutrons. However, it is not certain that the relatively high thermal fluxes given for the STARFIRE first-wall spectrum should be used for bulk materials due to neutron shielding effects. If we compare our measurements with the $14 \mathrm{MeV}$ cross sections used in that study, we find that the ${ }^{63} \mathrm{Cu}(\mathrm{n}, \mathrm{p})$ values are $80 \%$ higher, the ${ }^{60} \mathrm{Ni}(\mathrm{n}, 2 \mathrm{n})$ values are 3.0 times higher, the ${ }^{94} \mathrm{Mo}(\mathrm{n}, \mathrm{p})$ values are about $50 \%$ lower, values for ${ }^{92} \mathrm{Mo}(\mathrm{n}, 2 \mathrm{n}){ }^{91} \mathrm{Nb}$ are $40 \%$ higher, and those for ${ }^{93} \mathrm{Mo}$ and ${ }^{93 m} \mathrm{Nb}$ from ${ }^{94} \mathrm{Mo}$, as well as other reactions not mentioned, are quite similar. Hence, we would expect that the activity levels would scale accordingly if we included secondary effects due to thermal neutrons and side reactions as done in reference 20 . Of course, since we cannot separate the ${ }^{93} \mathrm{Mo}$ and ${ }^{93 \mathrm{~m}} \mathrm{Nb}$ reactions, ir is likely that the activity levels will be substantially reduced from those in previous calculations ${ }^{20}$. For example, if the cross section for the ${ }^{93} \mathrm{Mo}$ is only about 280 $\mathrm{mb}$, as discussed earlier, then the fusion reactor activity will be reduced to only $14 \mathrm{mCi} / \mathrm{cc}$. In any case, it is probable that there will still be stringent limits on the presence of $\mathrm{Mo}$ in fusion reactors if we are to meet the NRC requirements for 
class $\mathrm{C}$ waste disposal. The implications of these activities for fusion reactor design depend crucially on the details of the design as well as our assumptions regarding future regulations for the disposal of waste materials.

\section{Acknowledgements}

This work was supported by developmental funding from the Analytical Chemistry Laboralory at Argonne and by the Office of Fusion Energy, U. S. Department of Eaergy. We would also like to thank the staff of the RTNS II facility for assisting with the neutron irradiations. 


\section{References}

1. L. R. Greenwood, Recent Research in Neutron Dosimetry and Damage Analysis for Materials Irradiations, Symp. on Effects of Rad. on Mater., Seattle, June 1986, ASTM-STP956, in press.

2. L. R. Greenwood, D. G. Doran, and H. L. Heinisch, Phys. Rev. 34C,76-80(1987).

3. D. W. Kneff, B. M. Oliver, H. Farrar IV, and L. R. Greenwood, Nucl. Sci. Eng. 92,491-524(1986).

4. R. K. Smither and L. R. Greenwood, J. Nucl. Mater. 122, 1071-1077(1984).

5. R. K. Smither and L. R. Greenwood, Damage Analysis and Fundamental Studies Prog. Rep. DOE/ER-0046/17,11-13 (1984).

6. R. K. Smither, L. R. Greenwood, and H. Hendel, Rev. Sci. Instrum. 56,10781080(1985).

7. D. L. Bowers and L. R. Greenwood, Analysis of Long-Lived lsolopes by Liquid Scintillation Spectrometry, Proc. Int. Conf. on Meth. and Appl. of Radioanalytical Chem., Kona, Hawaii, A pril 1987, to be published.

8. L. R. Green wood and D. L. Bowers, Measurement of Long-Lived Isotopes in Fusion Materials, Proc. Sixth ASTM-EURATOM Symp. on Reactor Dosimetry, Jackson, WY, June 1-5, 1987, to be published.

9. D. R. Nethaway, J. Inorg. Nucl. Chem. 40,1285(1978).

10. E. Browne and R. B. Firestone, Table of Radioactive Isotopes, V. S. Shirley,Ed., John Wiley, New York (1986).

11. Fujino, NEANDC(J)-51U,p.60(1977).

12. S. Amemiya, Nucl. Sci. Tech. 19,p. 781(1982).

13. Katoh, NEANDC(J)-116,p.75(1985).

14. R. C. Haight, S. M. Grimes, R. G. Johnson, and H. H. Barschall, Phys. Rev. C23,700(1981).

15. S. PearIstein, Nucl. Cross Sections for Tech., NBS-SP425,332(1975).

16. M. Bormann, H. K. Feddersen, H. H. Holscher, W. Scobel, and H. Wagener, Z. Pinys. A277,203(1976).

17. Y. Kanda, Nucl. Phys. A $185,177(1972)$.

18. W. Lu, N. Kumar, R. Fink, Phys. Rev. C1,350(1970).

19. STARFIRE - A Commercial Tokamak Fusion Power Plant Study, ANL/FPP-80-1, September 1980.

20. H. L. Heinisch, F. M. Mann, and D. G. Doran, Fusion Technol. 8,2704-2707(1985). 
Table I: Long-lived Activities in Fusion Materials

\begin{tabular}{|c|c|c|c|}
\hline Isotope & Half-life, $y$ & Reactions & Status \\
\hline${ }^{14} \mathrm{C}$ & 5730 & ${ }^{14} N(n, F)$ & in progress \\
\hline${ }^{26} \mathrm{Al}$ & $7.2 \times 10^{5}$ & ${ }^{27} \mathrm{Al}(\mathrm{n}, 2 \mathrm{n})$ & Puef 4 \\
\hline${ }^{53} \mathrm{Mn}$ & $3.7 \times 10^{6}$ & $\begin{array}{l}{ }^{54} \mathrm{Fe}(\mathrm{n}, 2 \mathrm{n}) \beta \\
{ }^{54} \mathrm{Fe}(\mathrm{n}, \mathrm{d}+\mathrm{np})\end{array}$ & $\begin{array}{c}\text { Ref } 5 \\
\text { Planned }\end{array}$ \\
\hline${ }^{55} \mathrm{Fe}$ & 2.73 & ${ }^{56} \mathrm{Fe}(\mathrm{n}, 2 \mathrm{n})$ & Ref 8 \\
\hline${ }^{63} \mathrm{Ni}$ & 100. & $\begin{array}{l}{ }^{63} \mathrm{Cu}(\mathrm{n}, \mathrm{p}) \\
{ }^{64} \mathrm{Ni}(\mathrm{n}, 2 \mathrm{n})\end{array}$ & $\begin{array}{l}\text { Ref } 8 \\
\text { Ref } 8\end{array}$ \\
\hline${ }^{59} \mathrm{Ni}$ & $7.6 \times 10^{4}$ & ${ }^{60} \mathrm{Ni}(\mathrm{n}, 2 \mathrm{n})$ & Ref 8 \\
\hline${ }^{93} \mathrm{Zr}_{\mathrm{r}}$ & $1.5 \times 10^{6}$ & $\begin{array}{l}{ }^{94} \mathrm{Zr}(\mathrm{n}, 2 \mathrm{n}) \\
{ }^{93} \mathrm{Nb}(\mathrm{n}, \mathrm{p})\end{array}$ & $\begin{array}{l}\text { In progress } \\
\text { In progress }\end{array}$ \\
\hline${ }^{92} \mathrm{Nb}$ & $3.2 \times 10^{7}$ & ${ }^{93} \mathrm{Nb}(\mathrm{n}, 2 \mathrm{n})$ & In progress \\
\hline${ }^{91} \mathrm{Nb}$ & 680. & ${ }^{92} \mathrm{Nb}(\mathrm{n}, 2 \mathrm{n})$ & This work \\
\hline${ }^{94} \mathrm{Nb}$ & $2.0 \times 10^{4}$ & ${ }^{94} \mathrm{Nb}(\mathrm{n}, \mathrm{p})$ & Ref. 2 \\
\hline $93 \mathrm{~m} N$ & 13.6 & ${ }^{94} \mathrm{Mo}(\mathrm{n}, \mathrm{x})$ & This work \\
\hline${ }^{93} \mathrm{Mo}$ & 3500. & ${ }^{94} \mathrm{Mo}(\mathrm{n}, 2 \mathrm{n})$ & This work \\
\hline
\end{tabular}




\section{Table II}

Fe Isotopic Mass Spectrometry Measurements ${ }^{a}$

(Values are atomic percents)

(Calculations based on ENDF/B-V $V^{9}$ )

Fluence $\quad{ }^{54} \mathrm{Fe} \quad{ }^{56} \mathrm{Fe} \quad{ }^{57} \mathrm{Fe} \quad{ }^{58} \mathrm{Fe}$

$\left(10^{26} \mathrm{n} / \mathrm{m}^{2}\right)$ Exp. Calc. Exp. Calc. Exp. Calc. Exp. Calc.

$\begin{array}{rrrrrrrrr}6.37 & 5.02 & 5.01 & 78.36 & 77.70 & 14.84 & 15.00 & 1.28 & 1.68 \\ 3.48 & 5.33 & 5.35 & 83.54 & 83.73 & 10.12 & 9.73 & 0.70 & 0.80 \\ 3.21 & 5.41 & 5.39 & 84.83 & 84.83 & 8.86 & 9.21 & 0.59 & 0.74\end{array}$

$\begin{array}{lllll}\operatorname{Mean}(\mathrm{C} / \mathrm{E}) & 0.999 & 0.996 & 1.003 & 1.23\end{array}$

${ }^{a}$ Uncertainties: ${ }^{54} \mathrm{Fe} 0.4 \%,{ }^{56} \mathrm{Fe} 0.07 \%,{ }^{57} \mathrm{Fe} 0.3 \%,{ }^{58} \mathrm{Fe} 1.2 \%$ 
Table III: Mo Cross Section Measurements

\begin{tabular}{ccc} 
Reaction & Energy, $\mathrm{MeV}^{a}$ & $\sigma, \mathrm{mb}$ \\
\hline${ }^{92} \mathrm{Mo}(\mathrm{n}, 2 \mathrm{n})^{91^{9} \mathrm{Nb}}$ & 14.7 & $603 . \pm 119^{b}$ \\
${ }^{94} \mathrm{Mo}(\mathrm{n}, \mathrm{x})^{93} \mathrm{Mo}$ & 14.7 & $\prec 810^{c}$ \\
${ }^{94} \mathrm{Mo}(\mathrm{n}, \mathrm{x})^{93 \mathrm{~m}} \mathrm{Nb}$ & 14.7 & $\prec 26^{d}$
\end{tabular}

${ }^{a}$ Mean energy; width $\approx 0.5 \mathrm{MeV}$

${ }^{b}$ Uncert.: Stat. $1 \%$, std. $2.4 \%, \mathrm{~T}_{1 / 2} 19 \%$, fluence $5 \%$, net $20 \%$ cUncert.: Stat. $1 \%$, std. $2.4 \%, \mathrm{~T}_{1 / 2} 20 \%$, fluence $5 \%$, net $21 \%$ ${ }^{d}$ Uncert.: Stat. $1 \%$, std. $2.4 \%, \mathrm{~T}_{1 / 2} 2.2 \%$, fluence $5 \%$, net $6 \%$ 
Table IV: Fusion Reactor Activation Calculations (STARFIRE design, 21.6 MW-y $/ \mathrm{m}^{2}, 3000$ day cooling)

\begin{tabular}{ccc} 
Material & Isotope & Activity,mCi/cc \\
\hline Iron & ${ }^{55} \mathrm{Fe}$ & $25,000$. \\
Copper & ${ }^{63} \mathrm{Ni}$ & 1795. \\
Nickel & ${ }^{63} \mathrm{Ni}$ & 227. \\
& ${ }^{59} \mathrm{Ni}$ & 0.99 \\
Molybdenum & ${ }^{91} \mathrm{Nb}$ & 243. \\
& ${ }^{94} \mathrm{Nb}$ & 0.77 \\
& ${ }^{93} \mathrm{Mo}$ & $\prec 41$. \\
& ${ }^{93 m} \mathrm{Nb}$ & $\prec 140$.
\end{tabular}

